\title{
RESENHA DE ESCRITOR POR ESCRITOR - MACHADO DE ASSIS SEGUNDO SEUS PARES
}

\author{
REVIEW OF ESCRITOR POR ESCRITOR - MACHADO DE ASSIS SEGUNDO \\ SEUS PARES
}

GUIMARÃES, Hélio de Seixas; LEBENSZTAYN, Ieda (Orgs.). Escritor por escritor: Machado de Assis segundo seus pares, 1908-1939. São Paulo: Imprensa Oficial do Estado de São Paulo, 2019. 408 p.

GUIMARÃES, Hélio de Seixas; LEBENSZTAYN, Ieda (Orgs.). Escritor por escritor: Machado de Assis segundo seus pares, 1939-2008. São Paulo: Imprensa Oficial do Estado de São Paulo, 2019.612 p.

\section{Luís Bueno}

Universidade Federal do Paraná

Curitiba, Paraná, Brasil

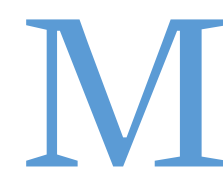
achado de Assis morreu em 28 de setembro de 1908. Logo no dia de 30 de outubro, Mário de Alencar, amigo muito próximo em seus últimos anos de vida, escreveu texto em que procurava descrever o escritor recentemente desaparecido. Para ilustrar a afirmação de que se tratava de pessoa "afável, de maneiras quase humildes" que "opunha um polido embaraço à sem-cerimônia, à exuberância”, conta uma anedota que seria depois muito repetida. Encontra-se o autor de Dom Casmurro com um velho conhecido que age com expansividade, "com intimidades brasileiras", elogiando-lhe muito um livro recente. Depois que o sujeito se decide a ir embora, o velho escritor diz simplesmente: "É um sujeito derramado. Faz-me mal aos nervos"

Tal anedota pretende esclarecer algo sobre o homem, não sobre o escritor, mas acaba servindo para os dois que, é claro, são um só. O proverbial recato das maneiras de Machado, seu esforço em preservar a vida pessoal, de jamais falar de si, pode ser visto como uma espécie de contraparte de seu estilo direto, sem exageros nem linguísticos nem narrativos. 
Escritor por escritor: Machado de Assis segundo seus pares traz o texto de Mário de Alencar ao lado de outros 116 dedicados por escritores ao nosso maior escritor nos cem anos que se seguiram à sua morte, reunidos e apresentados por Hélio de Seixas Guimarães e Ieda Lebensztayn. Contrariando a contenção machadiana, é preciso dizer que o conjunto constitui um painel riquíssimo ao colocar nas mãos do leitor uma miríade de histórias e julgamentos sobre o bruxo do Cosme Velho, de forma que ao final da leitura todos nos sentimos próximos dele, como aquele velho conhecido que brasileiramente o abordou na rua. Intimidade falsa, é verdade, mas a possível com o homem morto há tantos anos, de quem pouco se sabe e que deixou obra enigmática.

Mas não é somente de Machado que nos aproximamos, é também de cem anos de literatura brasileira, já que quem fala algo sobre ele conta ainda mais sobre si. E sobre si revelam muito aqueles que se mostram desconfiados em relação ao mestre. E na antologia há desconfianças de todo tipo.

Há desconfianças impulsivas, como a de Dinah Silveira de Queiroz, que relê toda a obra para concluir que apenas três romances e uma coleção de contos justificariam a fama e sustentariam a grandeza do escritor. Há as que se desfazem, como a de Monteiro Lobato, que, também após uma releitura, diz-se envergonhado de "juízos anteriores em que, por esnobismo ou bobagem, me atrevi a fazer restrições irônicas sobre tamanha obra”, ou como a de Ferreira Gullar, que decide retomar Dom Casmurro com rigor e espírito iconoclasta só para confessar que "investido de toda isenção, iniciei a minha releitura e, logo no primeiro parágrafo, já estava de novo enfeitiçado”.

Há desconfianças mais pessoais, por assim dizer, como a de Jorge Amado, cujo comentário, de 1977, foca na decisão de Machado de excluir as mulheres da Academia, chegando a afirmar que para consolar Júlia Lopes de Almeida ele teria integrado ao grupo fundador da casa Filinto de Almeida, seu marido. A mesma Júlia Lopes de Almeida que, na semana seguinte à morte de Machado, publicara um texto contando ter conhecido Machado antes de ser escritora, ainda menina. E ter sido com ele que pela primeira vez dançara "num salão de cerimônia”, desenhando uma figura jovial, bem-humorada.

Mas há também desconfianças profundas, como a revelada por Mário de Andrade, que explicita o incômodo de ter que escrever algo no contexto de homenagem ao centenário de nascimento de Machado, afirmando que "foi um homem que me desagrada e que eu não desejaria para o meu convívio". No entanto, confessa ser admirador de sua obra, incluindo parte de sua poesia, tão pouco lembrada em toda a coletânea. Ao Machado de Assis de Mário de 
Andrade faltam "generosidade, confiança na vida e no homem, a esperança" como aliás ao de Jorge de Lima "falta interesse ao coletivo". O poeta da Pauliceia desvairada procura explicar pela diferença de temperamento essa repulsa, mas é claro que não é somente isso. Sua arte propositiva, sua procura pelo anticonvencional, sua atividade intelectual fortemente gregária e a obra que se irradia toda de um eu em constante expansão é também muito diferente da obra contida de Machado. Ao separar o homem desagradável da obra genial, Mário de Andrade simplifica a questão para ao mesmo tempo reconhecer a importância central do velho escritor e afirmar sua própria forma de ver a arte e sua atuação intelectual. Fica sempre a curiosidade de imaginar o que o Mário de Andrade do final da vida, aquele cheio de melancolia e dúvida sobre a ação cultural construtiva e coletiva que empreendeu, o que escreveu "Meditação sobre o Tietê" pensava do homem que, em 1939, parecia-lhe sem generosidade.

Décadas depois, é Glauber Rocha quem se mostra ainda mais radical em sua desconfiança. O cineasta abundante, barroquizante, contrasta Machado e Alencar, preferindo claramente este, cuja obra é caracterizada como "o encontro do Negro com o Solimões", enquanto a do primeiro seria "água encanada”. Aqui não há separação entre homem e obra porque em 1976 Alencar seria MDB e Machado o "patrono da velha bossa da Arena". Para o diretor, portanto, não é preciso enfrentar nenhum dilema porque a Machado e sua obra faltam o gesto largo, a abundância, o derramamento que, não por acaso, no velho texto Mário de Alencar ligara às "intimidades brasileiras". Glauber, aliás, encontra-se ao lado de outro artista genial que tende antes ao excesso do que à contenção, Guimarães Rosa. Em trecho de diário citado na introdução dos organizadores ao segundo volume, simplesmente diz, aos 31 anos de idade, que não lerá mais Machado tanto por ser "antipático de estilo, cheio de atitudes" como pelas ideias, "nada mais do que uma desoladora dissecação do egoísmo".

Há, por outro lado, desconfianças menos claras. O mais barroco dos poetas concretos, Haroldo de Campos, não desconfia. Identificando a estética concreta com um estilo seco, "pobre”, coloca a poesia de Augusto de Campos no ponto de chegada de uma linhagem inaugurada por Machado com continuação no modernismo (a poesia de Oswald de Andrade, não a de Mário) e diretamente ligada a Graciliano Ramos (apesar das restrições do alagoano ao modernismo paulista), e daí a João Cabral.

Já Lima Barreto, que desconfia de tudo, é claro que desconfia da contenção de Machado, como confessa em carta de 1921 a Austregésilo de Athayde. Mas sua desconfiança faz parte de um pensamento crítico de maior 
alcance, de forma que dois anos antes já desconfiara dos excessivos elogios a Machado, feitos por Pedro Lessa na Academia, segundo os quais Machado era um puro abstrato, desligado da vida real: "Essa arte algébrica de descrição de sentimentos puros: amor, ciúme, orgulho, vaidade etc., não conheço, nem em Machado de Assis. Enfim, sou ignorante".

Essa atitude rompe com a identificação apressada entre estilo seco e indiferença à vida. Lima - que, diga-se de passagem, tem sua obra claramente reconhecida pelos seus pares, em diferentes textos, alçando-se seu prestígio quase à altura do de Machado - inaugura dessa maneira uma transformação na percepção sobre que o segundo volume da antologia aos poucos consolida. Machado aos poucos deixa de ser a criatura preocupada exclusivamente com sua própria ascensão social, avesso a todo movimento coletivo, seja como reação à revelação de novos textos (como os compilados por Galante de Sousa nos anos 50), seja mesmo como percepções de leitura rapidamente anotadas, como a de que sua obra "satirizava as classes dominantes" (Oswald de Andrade, 1939) e de que a desconversa dos narradores machadianos é retrato do “oportunismo brasileiro” (Décio Pignatari, 1971). Ou seja, a percepção que hoje temos, de uma obra que integra rigor formal e comentário do real, já fora intuitivamente formulada por vários escritores desde os primeiros anos que sucederam à morte do escritor.

Como essa, as grandes mudanças de visão crítica sobre Machado no decorrer de um século também são perceptíveis na mais popular das questões que suscita: afinal, Capitu traiu ou não Bentinho? É curioso observar que o grupo dos que defendem a existência do adultério, em textos mais recentes, de 1992, 1994 e 2005, é composto por homens nascidos na década de 1920 e formados ainda na primeira metade do século: Otto Lara Resende, Millôr Fernandes e Dalton Trevisan, verdadeiros militantes da causa. Como a defesa desse ponto de vista implica uma leitura menos desconfiada não de Machado, mas de Bentinho, a coletânea nos dá um instantâneo de uma alteração profunda na leitura de Dom Casmurro, mas não só.

Ao fixar em Machado de Assis um ponto de referência, o livro nos propõe uma visão de conjunto do escritor e da cultura brasileira. São poucos os momentos de aprofundamento de análise nos vários textos reunidos que, entretanto, enquanto conjunto, convidam o leitor a aprofundar-se na leitura que faz de Machado, da literatura brasileira e de suas próprias convicções críticas. Com isso, estimula o melhor dos movimentos que é a desconfiança sobre os consensos de nosso tempo e de nosso próprio pensamento. 


\section{Referências}

ALENCAR, Mário de. in GUIMARÃES, Hélio de Seixas; LEBENSZTAYN, Ieda (Orgs.). Escritor por escritor: Machado de Assis segundo seus pares, 1908-1939. São Paulo: Imprensa Oficial do Estado de São Paulo, 2019, p. 137-52.

CAMPOS, Haroldo de. in GUIMARÃES, Hélio de Seixas; LEBENSZTAYN, Ieda (Orgs.). Escritor por escritor: Machado de Assis segundo seus pares, 1939-2008. São Paulo: Imprensa Oficial do Estado de São Paulo, 2019, p 413-25.

PIGNATARI, Décio. in GUIMARÃES, Hélio de Seixas; LEBENSZTAYN, Ieda (Orgs.). Escritor por escritor: Machado de Assis segundo seus pares, 19392008. São Paulo: Imprensa Oficial do Estado de São Paulo, 2019, p 36372.

ROCHA, Glauber. in GUIMARÃES, Hélio de Seixas; LEBENSZTAYN, Ieda (Orgs.). Escritor por escritor: Machado de Assis segundo seus pares, 19392008. São Paulo: Imprensa Oficial do Estado de São Paulo, 2019, p 38392.

LUÍS BUENO é doutor em Teoria e História Literária pela Unicamp (2001) e professor de Literatura Brasileira e Teoria da Literatura na Universidade Federal do Paraná desde 1996. Publicou, além de artigos, alguns livros, entre os quais se contam Uma história do romance de 30 (Edusp/Unicamp, 2006, 2 ed. 2015), A tradição literária brasileira entre a periferia e o centro, organizado em colaboração com Germana Salles e Valéria Augusti (Argos, 2013), Capas de Santa Rosa (Ateliê/SESC, 2016), O hábito da perfeição - poemas de Gerard Manley Hopkins (Jabuticaba, 2018) e o romance Paradeiro (Ateliê, 2018).

(1D) 0000-0002-5062-5653. E-mail: luis@ufpr.br

Recebido: 19.10 .2020

-Aprovado: 15.11.2020 